\title{
TCOM \\ A space to study: expectations and aspirations toward science among a low-participation cohort
}

\section{Cherry Canovan and Robert Walsh}

Abstract

Keywords

DOI

Introduction
Widening participation in science is a long-held ambition of governments in the U.K. and elsewhere; however numbers of STEM entrants to university from low-socioeconomic status groups remain persistently low. The authors are conducting a long-term school-based space science intervention with a group of pupils from a very-low-participation area, and studied the science attitudes of the participants at the beginning of the programme. Key findings were that young people from the very-low-SES study cohort were just as interested in science study and science jobs as their peers nationally, and had a pre-existing interest in space science. Some participants, particularly boys, demonstrated a 'concealed science identity', in that they perceived themselves as a 'science person' but thought that other people did not. Boys tended to score higher on generalised 'science identity' measures, but the gender difference disappeared on more 'realist' measures. In addition, although participants agreed that it was useful to study science, they had little concrete idea as to why. These findings shed light on how science communicators can best address low-SES groups of young people with the aim of increasing their participation in science education and careers. We conclude that interventions with this group that focus on 'aspiration raising' are unlikely to be successful, and instead suggest that activities focus on how young people can see science as a realistic path for their future. It would be helpful for in-school programmes to allow young people an outlet to express their science identity, and to give information about the kinds of jobs that studying science may lead to. Further research into whether the gender split on idealist/realist measures of science identity persists over time would be of use.

Public perception of science and technology; Science education; Social inclusion

https://doi.org/10.22323/2.19060204

Submitted: 16 th July 2020

Accepted: 21st October 2020

Published: 9th December 2020
Widening participation (WP) in science to low-participation communities, including those in deprived areas, is a key U.K. public policy goal. Despite much 
effort, however, participation figures remain stubbornly low. Research into the science attitudes of school children reveals that while they are in general interested in science, this enthusiasm does not translate into a desire to 'become a scientist'.

One type of WP activity that merits attention is targeted long-term interventions, working with the same group over a number of years. One such intervention is Blackpool PIER (Physics: Inspire, Engage, Research), working in schools with a group of children from one of the U.K.'s most disadvantaged areas, the seaside town of Blackpool.

In order to better inform those planning interventions with target groups, our study investigated the initial science attitudes and identities of PIER participants at the start of the programme in year 6. It asked whether levels of interest in science are aligned with those of their peers nationally, whether our cohort saw themselves as 'science people', and whether they had an understanding of the usefulness of science.

Although raising participation in higher education [Office for Students, 2018] and science [Department for Business Energy and Industrial Strategy, 2017] among young people from low-socioeconomic status (SES) backgrounds is stated U.K. government policy, this ambition has so far proved hard to realise. Higher education participation remains stubbornly low in pockets of deprivation across the country [Higher Education Statistics Agency, 2018], with the physical sciences further underrepresented among those who do attend.

To address this issue, a number of studies have been done of young people's attitudes to science [e.g. Archer and Tomei, 2013; Reiss, 2013] and a wide variety of in- and out-of-school interventions have been carried out to try to broaden post-compulsory science participation [many examples exist; see, for example, Grove, 2013; Hobbs et al., 2019; Illingworth, Lewis and Percival, 2015; Wade, 2016]. However the efficacy of these have been called into question; Banerjee, who looked at progression data from GCSE to A level for 630,000 students, found that "Young people participating in STEM enrichment and enhancement activities did not have a greater likelihood of continuing with STEM subjects after compulsory education," [Banerjee, 2017].

One strand worthy of investigation is whether intensive, multi-year interventions with target groups of young people can yield better results. One such project is the STFC-funded Blackpool PIER project, which involves a series of around a dozen interventions by academics and science communicators with a group of school pupils from years $6-8$, across the primary-secondary transition. As well as assessing the efficacy of this type of longitudinal intervention, the project affords the opportunity to examine attitudes to science and higher education among young people from one of the U.K.'s most disadvantaged areas.

In this paper, we look at participants' attitudes to science at the start of the programme, before the first space science intervention. This enables us to investigate attitudes among a group of young people in an area of extreme deprivation; it allows us to test current ideas about the interplay between deprivation and aspirations/expectations for the future, and to investigate in detail 
the perspectives on science held by members of the group. This information can then be used to assess the most effective ways of communicating ideas about science and science careers to under-represented groups in order to increase their likelihood of future participation.

\subsection{Aspirations and expectations}

It has been noted by several commentators [e.g. Baker et al., 2014; Harrison and Waller, 2018] that much government policy towards boosting HE and science participation has followed an aspiration-deficit model, suggesting that inequalities arise at least in part from a lack of desire among low-SES groups to participate. However the evidence for this view is, in fact, lacking; in terms of higher education, at least, young people have uniformly high aspiration for their futures [Archer, DeWitt and Wong, 2014; St. Clair, Kintrea and Houston, 2013]. As Harrison and Waller note:
"An assumption that low aspirations undermine the demand for HE, especially for disadvantaged young people, has a long history; however, evidence for this is scant. Indeed, there has been a growing consensus from empirical studies that rather than being low, young people's aspirations (in this sense of a reported desire) for both HE and future careers are high..."

However differences are seen when a distinction is made between aspirations and expectations; in other words, between what we hope our future will be, and what we realistically think will happen. On this measure, groups with lower SES show a disconnect between aspirations and expectations which is much less evident among more privileged groups [Boxer et al., 2011; Khattab, 2015]. Khattab states that:

\footnotetext{
"Most children from disadvantaged socio-economic backgrounds are likely to develop a profile in which their aspirations, expectations and their actual academic outcomes are either misaligned or aligned at the lower end."
}

It is also the case that parents of young people in low-participation groups, although themselves not lacking in aspiration for their children, may be unsure as to whether these aspirations would be realised. Archer and DeWitt [Archer and DeWitt, 2017], who studied the aspirations and attitudes to science of young people aged 10-14 and their families, note that middle-class parents were confident that they would be able to help their children to overcome challenges. However,

\footnotetext{
"In contrast to many of the middle-class parents, the working-class parents often evoked a discourse of upward social mobility and 'doing better than I did'. But this was frequently couched in some uncertainty about whether this was attainable, due to the competitive nature of the job market..."
}

\subsection{Science attitudes and aspirations}

In terms of science, the picture is more complex. In general, although pupils in all groups enjoy science, very few young people across the board actually wish to 
pursue a career in science. The ASPIRES survey of 19,000 young people aged 10-14 [Archer, Osborne et al., 2013] found that only around 15\% stated a desire to become a scientist, despite around two-thirds stating that they learned interesting things in science and more than three-quarters holding the positive view that scientists "make a difference in the world" (p. 2).

The ASPIRES project and its successors developed an index of science capital [Archer, Dawson et al., 2015], based on factors such as engaging in out-of-school science activity, parents thinking that science was interesting and ideas about the usefulness of science; high levels of science capital are associated with future science study for young people. Relative affluence is not enough to predict post-compulsory science participation; high levels of science capital are also dependent on factors such as strong interest in science, confidence in scientific ability and a secure identity as a "science person" (p. 938).

Low science capital is, however, associated with low SES, meaning that low SES is also associated with low participation in post-compulsory science. This effect can be seen in HESA data [Higher Education Statistics Agency, 2018]; young people from low-participation backgrounds are even further underrepresented in maths, physical sciences and medicine (Figure 1).

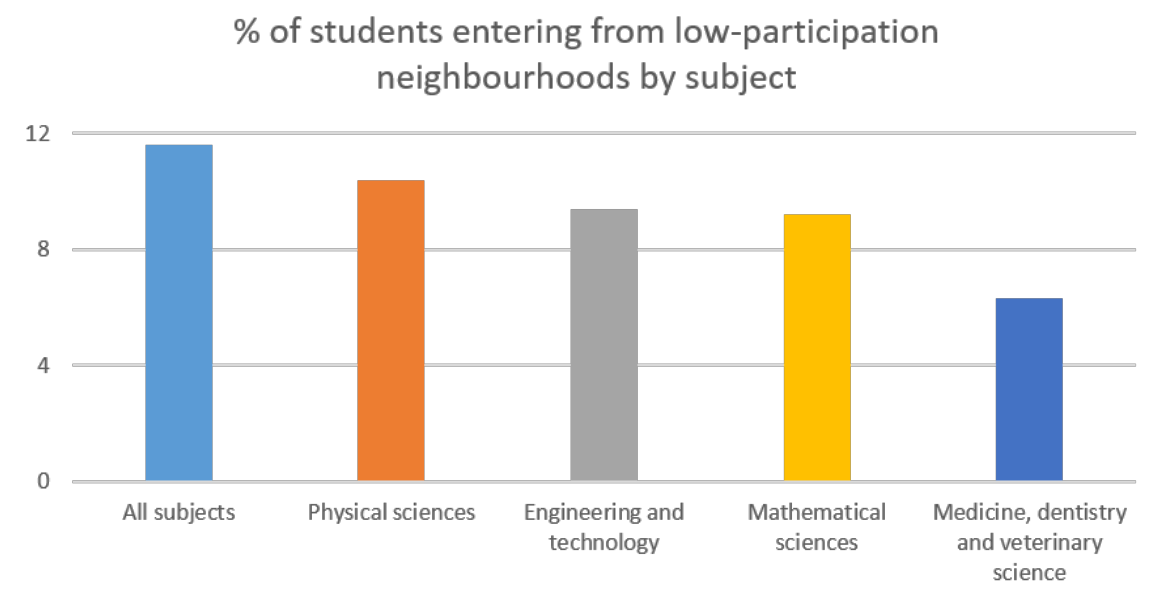

Figure 1. HESA widening participation data for young, U.K.-domiciled entrants for $2017 / 18$.

Having family or friends working in science is an important component of science capital; the importance of such role models for young people's aspirations is highlighted by Cochrane [Cochrane, 2010], and is often a component of widening participation practice [Robinson and Salvestrini, 2020]. Young people living in low-SES areas may not have access to science role models in their family life, which can prove an additional barrier to entering science-related careers.

\subsection{Science jobs and the utility of science qualifications}

Ideas about the usefulness of science are a very important factor when it comes to future science intention; it has been widely noted that in general, school pupils do not have a strong grasp of the extensive applicability of science qualifications and 
the breadth of science jobs available [Archer, DeWitt and Dillon, 2014; Canovan, 2019; Hill and Wheeler, 1991]. In addition, it has been shown that those young people who choose to pursue post-compulsory science qualifications are those with a greater understanding of the utility of science than is the norm [Cleaves, 2005].

This is not a problem which is specific to cohort lower-SES cohorts; reflecting on the ASPIRES study, Archer and DeWitt [Archer and DeWitt, 2017] note:

\footnotetext{
"Our study found that most parents and young people had relatively narrow views about where science qualifications lead, with the majority only being able to name scientist, science teacher or doctor as jobs that science qualifications lead to."
}

Pupils who do not understand where studying science may lead are less likely to continue with it at post-compulsory age; the choice, for example, to study post-16 physics is much more strongly influenced by career aspiration than by any other factor [Reiss, 2013]. It follows that an understanding of the breadth of science's usefulness in the jobs market can be a good starting point for encouraging future science participation.

It should be noted that there is not only an equity issue here - the underrepresentation of certain groups of people in areas of study that lead to highly-paid and highly-skilled work - but a broader consideration. Concerns about shortages of scientific skills in the U.K. workforce are well-documented; the government's 2018 Industrial Strategy [Department for Business Energy and Industrial Strategy, 2018] noted that

\footnotetext{
“... we need to tackle particular shortages of STEM skills. These skills are important for a range of industries from manufacturing to the arts. The number of STEM undergraduates has been increasing over the last few years, but there remains unmet demand from employers."
}

If we are to meet the challenge identified here, we cannot continue to rely on the small proportion of the population with high levels of science capital to fill STEM roles. Instead, we must find ways to broaden the appeal of post-compulsory science study among all underrepresented communities, including those such as the subject of this study.

\subsection{Research questions}

Given the above findings, our paper poses the following questions:

1. How do the aspirations and expectations relating to science of a group of $Y 6$ pupils from one of the U.K.'s most deprived areas compare to the national picture?

2. How does this cohort perceive their 'science identity'?

3. What understanding does this group have of science jobs and the utility of science qualifications? 
To explore our research questions, we carried out a study with participants at the beginning of the Blackpool PIER project. Here we analyse the initial science views and orientation of the cohort before any interventions; where appropriate, we draw comparisons with the results of the ASPIRES survey to highlight the similarities and differences of our group to the national picture.

\subsection{The Blackpool PIER project}

Blackpool PIER is a longitudinal project involving young people in an intensive series of space science interventions. The project, funded by the U.K. Science and Technology Facilities Council, is part of a Leadership Fellowship in Public Engagement programme conducted by Professor Robert Walsh (co-author). It follows a group of young people in partner schools from the beginning of Year 6 - the final year of primary school — through the transition to secondary school at the start of Year 7 and then on to the end of Year 8. The project aims to enhance science capital in four areas:

1. Science knowledge - learning facts about space science;

2. Who young people know - introducing them to people working in the field of space science;

3. Ideas about the utility of science and space science, including transferable skills and potential jobs/careers;

4. Informal and out-of-school science activity.

The project began in 2017 and was originally scheduled to last for three years; however delivery was impacted by the Covid-19 pandemic, and at the time of writing (2020) is in an extended phase. Results of the interventions will be published in due course.

PIER is targeted at young people in low-science capital, low-participation areas of Blackpool, a large seaside town in North West England. Blackpool is a famous seaside resort, with its iconic Tower and annual Illuminations, but is also one of the U.K.'s most disadvantaged areas, by some measures England's most deprived local authority district. In some areas of Blackpool, only $16 \%$ of young people go to university at age 18-19 [Office for Students, 2019], compared to around one-third across the U.K. [UCAS, 2017]. Data from the 2011 census showed that the town had high levels of unemployment (6.1\% compared with $4.4 \%$ across England) and long-term sickness (7.9\% compared with $4.0 \%)$. It is also somewhat geographically isolated, situated at the end of the Fylde peninsula surrounded by large tracts of open farmland. Blackpool is much less ethnically diverse than England as a whole, with BAME groups making up around 3\% of the population compared to around $14 \%$ nationally ${ }^{1}$ at the time of the 2011 census.

The schools involved in the project, both at primary and secondary level, have very high levels of pupils attracting the Pupil Premium, extra funding provided by the government to help disadvantaged pupils perform better. All three primary

\footnotetext{
${ }^{1}$ http://www.blackpooljsna.org.uk/Blackpool-Profile/Ethnicity.aspx.
} 
schools and two secondary schools involved were in the top $2 \%$ of schools by percentage of Pupil Premium across England in the year in which their stage of the PIER programme started [Education and Skills Funding Agency, 2016; Education and Skills Funding Agency, 2017]. Pupil premium is related to current or past entitlement to free school meals, which is highly correlated with educational disadvantage [Greaves and Crawford, 2013].

All schools reflect the ethnic distribution of the local area, with $90 \%+$ white pupils compared to around $75 \%$ nationally, ${ }^{2}$ although one had a higher-than-average proportion of pupils from non-British backgrounds. White British pupils receiving free school meals are known to achieve the lowest GCSE grades, among both boys and girls [Kirby and Cullinane, 2016].

The project consists of a series of three interventions in every school year: a 'Meet the Scientist' session, where a working scientist visits a school to run an activity; a visit to the Alston Observatory at the University of Central Lancashire (UCLan); and a day at the Young Scientist Centre in Preston, a joint venture between UCLan and the Royal Institution. In addition, once the pupils reach secondary level, they have opportunities to participate in family events, similar to miniature science festivals, at their school. A total of 11 interventions with academics and science communication professionals over three academic years were originally planned, although Covid-19 restrictions have meant some alterations to the programme and its extension to four years. Interventions were designed before the baseline study was conducted, although some amendments were subsequently made to take account of the findings.

In all, 94 pupils have participated in at least one stage of the project. Recruitment was complicated by the fact that the project extends across the primary-secondary transition, meaning that a few pupils dropped out at the end of year 6 and a few joined at the beginning of year 7 .

As well as assessing the ability of such an intensive project to improve interest in and knowledge of science, this project allows us to interact with the cohort of young people on multiple occasions over three (now four) years. We are therefore able to make an in-depth study of their attitudes to science and to higher education more generally, the initial results of which are presented here.

\subsection{Data collection}

To assess the efficacy of the project in the four areas outlined above, participating pupils completed a number of surveys and other assessments. All participants took an online baseline survey when they joined the project to assess their levels of science capital and views on science more generally; this is repeated at various points to track progress, if any. Qualitative assessment exercises are also undertaken at various points during the project.

This paper focuses on the initial results of the year 6 baseline survey of 74 pupils, alongside 48 one-to-one interviews with some of these participants. As mentioned,

\footnotetext{
${ }^{2}$ https: / / assets.publishing.service.gov.uk/government/uploads/system/uploads / attachment_data/file/650547/SFR28_2017_Main_Text.pdf.
} 
there has been a certain amount of attrition among the original participants, with others joining later; however this paper focuses on year 6 joiners only.

The initial PIER cohort consisted of 74 year 6 pupils across three primary schools. Of these, 30 were boys and 44 girls. This disparity is not due to any targeted effort; whole primary classes were invited to participate in the project, and the differential in numbers of girls and boys is due to normal variability.

The baseline survey, hosted online, was administered in a classroom setting in participating schools. As well as the class teacher, the authors were present, including Robert Walsh, who would be conducting the PIER programme. Both authors are white, middle-class university professionals. The survey consisted of 25 multiple-choice questions on topics such as participants' family backgrounds, attitudes to education and attitudes to/interest in science, and took around 20 minutes to complete. The survey instrument was developed with reference to the ASPIRES survey, to provide a degree of comparability between our cohort and the national picture.

Following the surveys, researchers conducted one-to-one interviews with a number of participants. These interviews were structured and took around 10 minutes each. Interviews were recorded and transcribed and the data was analysed using inductive thematic analysis; the material was read several times to ensure familiarity with the content, and was then tagged with a series of initial codes. These codes were then examined to develop overarching themes, with the codes themselves revisited in light of this analysis.

It should be noted that participants knew that they were about to embark on a science-based programme of activities, meaning some intervention effects were inevitable. We thought it likely that contributors might express more positive scientific attitudes than they would do in a more neutral setting; this effect is taken into consideration during the following discussions.

\section{Results and discussion}

\subsection{Aspirations and expectations relating to science}

\subsubsection{Interest in science}

Most participating pupils stated that they were interested in science. A total of 48 year 6 students took part in one-to-one interviews with researchers after completing the initial survey but before any science interventions took place; of these, 37 (77\%) stated unreservedly that they were interested in science, with a further six stating they were 'a bit' interested. This correlates well with the $74 \%$ of year 6 respondents in the ASPIRES study who agreed that they 'learn interesting things in science lessons'.

This interest in science was reflected in the fact that a majority $(44 / 74)$ of survey respondents reported consuming science media, for example books, TV or science websites, at least once a week. In interviews, multiple participants reported watching nature TV shows such as Blue Planet, with online space-related content such as SpaceX rocket launches also popular. 
Our cohort were generally confident about their scientific abilities. Just over half (51\%) reported knowing "quite a lot" about science, while two-thirds said they were confident giving answers in science lessons. Attitudes to science were also positive, with only $19 \%$ agreeing that "science has no personal meaning for me" while only $16 \%$ agreed that "doing science makes me unhappy".

PIER students generally reported feeling more positively about science in relation to their own future than the national ASPIRES cohort [Archer and DeWitt, 2017]. For example, we asked whether or not young people would like to be scientists or have jobs involving science (Figure 2):

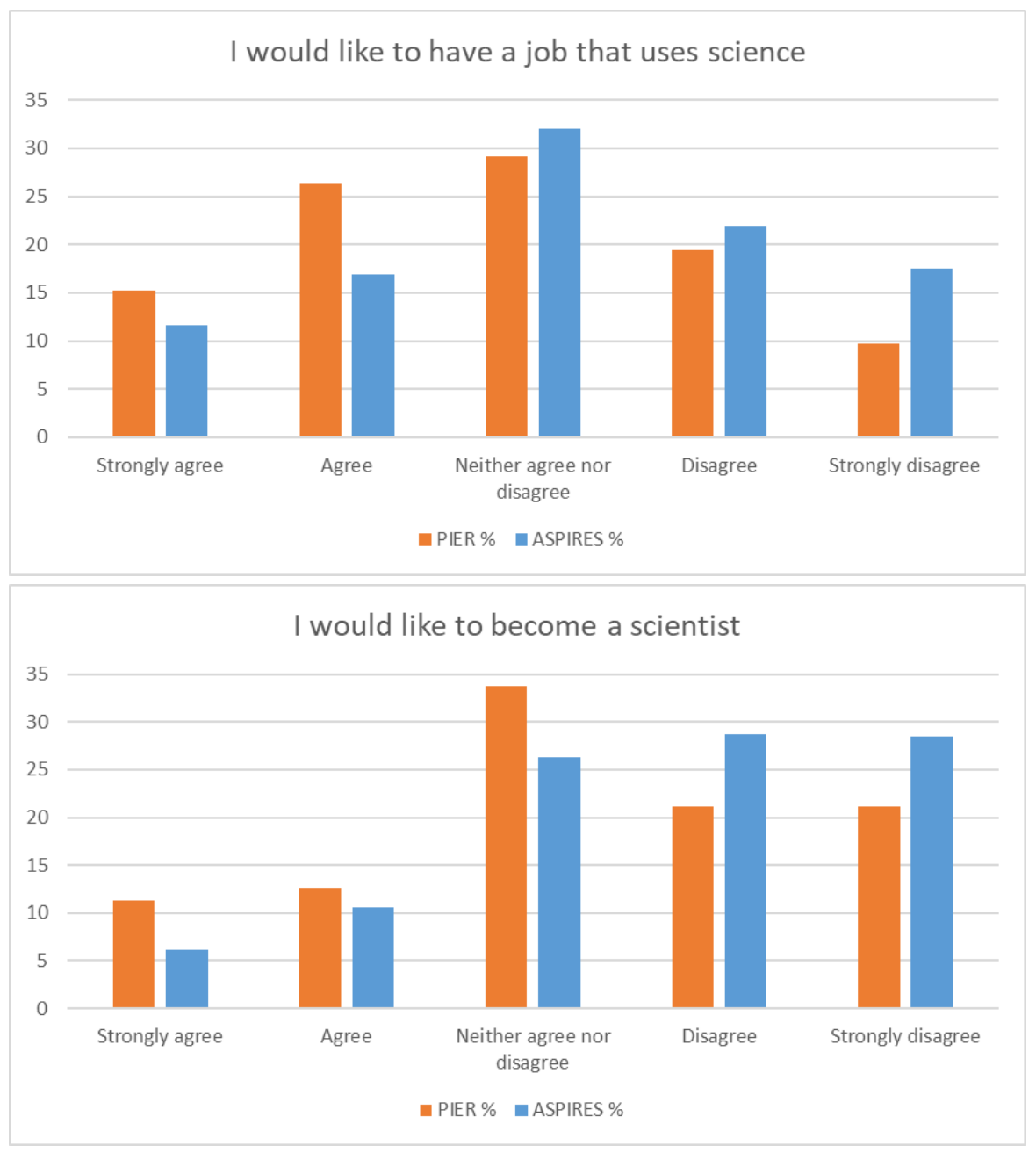

Figure 2. Our PIER group were somewhat more positive about their scientific futures than the comparable national cohort.

This tendency to be somewhat more positive about various aspects of science than the national cohort was evident across several measures in our survey - for example, $61 \%$ stated that they would like to study science in some form after GCSE, which we can compare with the $40 \%$ of ASPIRES respondents who stated that they "would like to study more science in the future". As discussed, we surmise that there may be an intervention effect here - the ASPIRES cohort completed the survey under the aegis of their class teacher, with no additional context, while PIER participants were aware that they were about to embark on a space science project and had been introduced to participating academics. 
However even when this factor is taken into account, the results align with the national picture and there is no evidence that our group felt less positively about science than their peer group nationally.

As in the national group, this enthusiasm about science did not translate into a desire to pursue a scientific career. Although more than three-quarters of PIER interviewees stated that they were interested in science, only $42 \%$ of those surveyed would like to have a job that uses science, while less than a quarter $(24 \%)$ would like to "become a scientist".

\subsubsection{Family attitudes to science and HE}

Our participants were also very positive about their families' attitudes to science, with $75 \%$ agreeing or strongly agreeing with the statement: "The people who usually look after me think science is very interesting". They were also firmly of the opinion that their families saw science as an important facet of their education; $87 \%$ agreed or strongly agreed with the statement: "The people who usually look after me think it is important for me to learn science".

Our participants were again more positive on these points than the respondents to the national ASPIRES survey [Archer and DeWitt, 2017], for whom the comparable figures were 59\% [the related ASPIRES question was less strongly phrased as "My parents think science is interesting"] and $72 \%$. Again, we must caution about intervention effects in these results.

However when it comes to children's perceptions of their parents' expectations for their future, the picture is reversed. When asked to respond to the statement " $(\mathrm{My}$ parents) expect me to go to university", $62 \%$ agreed or strongly agreed, compared with $68 \%$ of the ASPIRES cohort. The difference was almost entirely in the 'strongly agree' category - $40 \%$ of the ASPIRES cohort compared to $30 \%$ of the PIER group - indicating a lower degree of certainty among our PIER cohort than among the national sample (Figure 3 ).

My parents/the people who look after me:

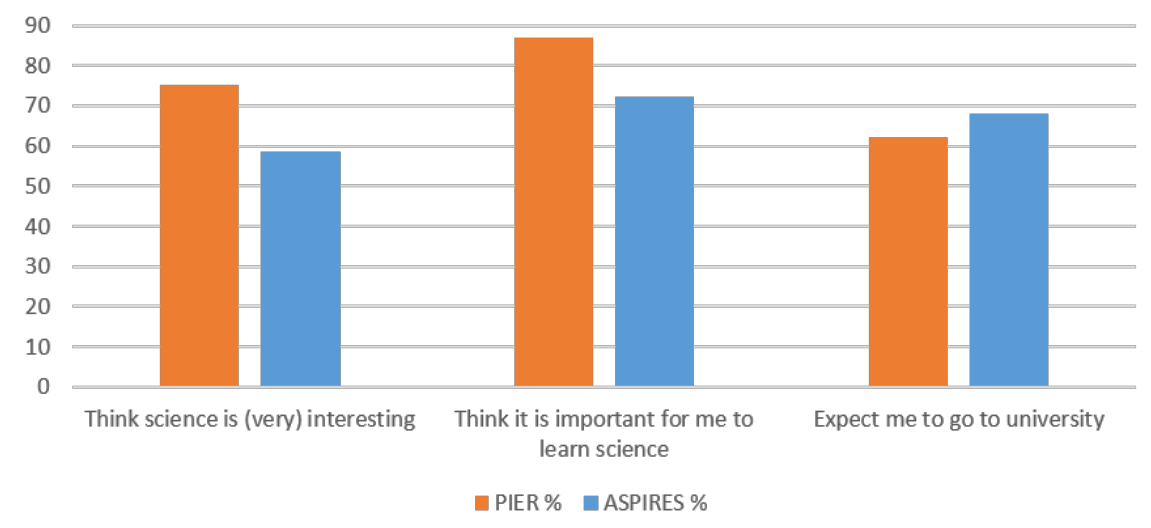

Figure 3. PIER participants' views of their parents science and HE attitudes. 


\subsubsection{Space science}

Space science was a very popular subject amongst our cohort, with almost all $(57 / 66)$ agreeing with the statement "I am interested in the science of outer space", and 38 of those (58\% of the total) strongly agreeing.

In the pre-intervention interviews, the aspect of science cited as interesting by the greatest number of pupils was space and related subject such as rocketry, with $21 / 48$ interviewees mentioning these topics. For example, participant Rose [participants were asked to choose an alias for themselves to be quoted under in research publications] said: "The main thing I like is space and stuff, I like finding out how Earth and the Sun existed".

While this response may have been influenced by the fact that the pupils were aware that they were going to participate in a space-science related project, there was clearly an existing interest in the topic for many respondents. Some mentioned having previously participated in a space-related trip with school, while others cited having previously studied the subject in class. For example, when asked what aspects of science he was interested in, participant Unicorns said:

"Space and how the Sun and Earth and other planets work. I think we done science in space ages ago. A year or two ago."

Several pupils stated that they were interested in rockets, with some citing the SpaceX launches which had recently taken place. Alex said: "I normally go on my tablet and watch all science stuff. [I] watch rocket launches on my tablet, do that nearly every night".

However the disparity between interest and ambition seen in the wider field of science was also observed in the area of space science. While $41 \%$ agreed that they would like to work in the space industry in the future, less than a quarter $(24 \%)$ agreed that "I could become a rocket scientist".

\subsubsection{Discussion}

Our results indicate that primary-age pupils from an extremely low-SES area are not any less interested in science than their peer group nationally. They also mirrored the national picture in the fact that their very high reported interest in science as a subject was not reflected in high levels of aspiration to have a job involving science or 'become a scientist'. It follows that targeted interventions in low-SES areas should not assume that levels of interest in science are lower than in more affluent areas; activities focused on raising interest or awareness are likely to be insufficient to affect outcomes.

When it comes to the influence of families, we see a divergence from the national ASPIRES data in line with what we might expect from the literature on disparities between aspirations and expectations among low-participation cohorts. Although pupils stated that their parents thought that science was interesting, and thought it was important for them to learn science, at higher rates than the national cohort, 
they were less sure when it came to entrance to higher education. Asked whether their parents expected them to go to university, the proportion agreeing among the PIER cohort was around 10 percentage points lower than among the ASPIRES cohort. Across the country, a relatively high proportion of around $40 \%$ of young people feel very sure that their parents expect them to go to university; however we would expect this to be a smaller group among low-participation cohorts, due to lack of family experience and financial concerns, and this expectation has proved correct. The effect is made more pronounced by the fact that on other, less concrete measures our cohort gave answers that were more enthusiastic than those of their broader peer group.

The PIER study is focused on space science in particular, and here participants reported even higher levels of interest and enjoyment. Although there is likely to be some heightened intervention effect in this area, given that participants knew they were going to study space science specifically, there is solid interview evidence that this was an existing area of interest for many of the cohort, with trips, lessons, media and space facts all cited to researchers.

\subsubsection{Key findings}

- Our very-low-SES group was just as interested in science and science jobs as the national cohort

- Participants were more likely than the national cohort to say that their parents were interested in science, but less likely to say that their parents expected them to go to university

- Participants had a significant pre-existing interest in space science

\subsection{Science identity}

\subsubsection{Self-image and science}

Although they enjoyed science, the majority of participants did not see themselves in a scientific light, with only $34 \%$ agreeing with the statement "I see myself as a science person". However even fewer $(24 \%)$ agreed with the statement "Other people think of me as a science person", suggesting a tendency of some respondents to experience an inner scientific life that they felt may not be visible to others - a 'concealed science identity'. In fact, of those who saw themselves as 'science people', only 38\% thought other people saw them in this way too. This was confirmed by responses given at the interview stage. Participant Unicorn said:

“...when I'm actually in science lessons, I don't really show that I'm paying much interest, but on the inside, I'm actually, like, really getting stuck into it and having lots of fun. It's just I don't really show that in the lessons."

This exchange with participant Savannah illustrates the point: 
Savannah: A lot... the stars and learning about the stars... I have a telescope that I use at home.

Interviewer: Do you think people would know about your interest in space or science and would say that you're sort of a science person?

Savannah: No... Because in school I'm more sporty and I don't do that much about science.

\subsubsection{Gender effects}

Our dataset included 30 boys and 44 girls; due to the small number of responses, we do not make any claims of high levels of significance for gender disparities in our findings. However some interesting points emerge, and as these are broadly in line with earlier findings on gendered science aspirations [e.g. OECD, 2015] we feel there is merit in reporting them.

On a number of measures of science attitude, we see higher levels of positivity among boys than girls. For example, $31 \%$ of boys agreed that "I want to become a scientist", compared to $19 \%$ of girls; the equivalent figures for "I see myself as a science person" were $39 \%$ and 30\%, and for "I could become a rocket scientist" the figures were $32 \%$ and $19 \%$. This is not a surprising finding. These results are consistent with numerous findings over many years (a good summary can be found in Osborne, Simon and Collins [2003]) that girls' attitudes to science are less positive than boys', particularly in physics. As Archer and DeWitt [Archer and DeWitt, 2017] note,

“...decades of investment and interventions aimed at encouraging more girls and women to continue with science seem to have had little impact on gendered patterns of STEM participation."

Although there is some evidence that participation is slowly changing - female entries for science A levels in the U.K. overtook male entries for the first time in 2019 [Joint Council for Qualifications, 2019] — participation is stubbornly low in physics, with female entries only $23 \%$ of the total. In this context, therefore, it is unsurprising that the girls in our sample were less enthusiastic/positive about science than the boys.

However, the distinction did not persist on every measure. For example, when presented with the statement "I would like to have a job that uses science", more girls than boys agreed ( $44 \%: 38 \%$ ). There was also no difference between the proportions of girls and boys stating that they would like to study post-compulsory science $(62 \%: 61 \%)$. It is interesting to note that boys were significantly more positive about science on 'identity' measures - for example, "I want to become a scientist" - but not on what we might term 'realist' measures, such as the idea that a future job might use science. These results are summarised below in Figure 4.

Returning to the question of 'concealed science identity', it is of interest that this was largely seen among boys. While $30 \%$ of girls saw themselves as science people, and $26 \%$ said other people saw them as science people, the equivalent figures for boys were $39 \%$ and $19 \%$. Although, as stated, numbers are small, this is an 


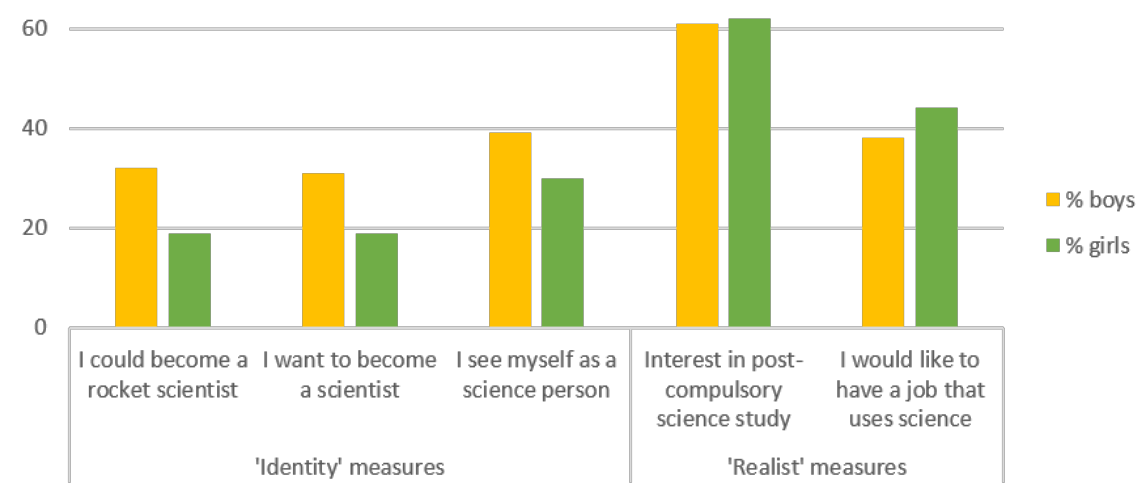

Figure 4. Boys were more positive than girls on 'identity' measures of science, but the disparity disappears on 'realist' measures.

interesting contrast. Our qualitative data give some hints as to why this might be; in our interviews, some boys indicated that to be a 'science person' would be at odds with a jokey persona or with a pressure to appear uninterested in lessons:

Interviewer: Do you think other people would say that you're sort of a sciencey person, that you're interested in science?

Shadow: I don't think so because I'm quite funny so most people would probably like me to be funny.

Interviewer: So you don't think you can be funny and also be a scientist?

Shadow: I think I could be both, but mostly joking.

Meanwhile among girls, there were some suggestions in our interviews that participants felt a tension between science interests and identities and their 'feminine' identity:

Interviewer: Are you interested in science?

$\mathrm{ABC}$ [This participant was assigned an alias]: Yes.

Interviewer: What parts of science are you interested in?

ABC: I don't know, like making things and the labs...

[...]

Interviewer: Do you think people would say that you're a 'sciencey person'?

ABC: Not really.

Interviewer: No? Why do you think they wouldn't say that?

ABC: Because, like, I'm a girly girl. I'm, like into shopping and things.

Interviewer: Oh, right, and does that mean you wouldn't be involved in science, then?

ABC: Yes, but people wouldn't know me to be a science kind of person.

This said, the majority of participants who stated that others did not see them as 'a science person' said that they didn't know why, or that they tended to talk about other things. 


\subsubsection{Discussion}

Our study suggests the existence of what we term 'concealed science identities' the perception that one sees oneself as a 'science person' to a greater extent than others do.

We saw some indication among the qualitative data that both boys and girls felt a tension between their interest in science and their public persona; some boys felt science was at odds with their jokey, unserious image, while some girls felt the same about their identity as 'girly girls'. However most respondents were uncertain as to the source of the disparity, or said it was because they did not often discuss or take part in science. It may be that a lack of opportunity to pursue science interests within the school setting, perhaps caused by competing curriculum pressures or practical difficulties such as setting up equipment, means that there is little chance for these science identities to reveal themselves.

Whether or not such concealed identities could negatively impact future science participation is an interesting question. One might speculate that a nascent interest which cannot find space for outward expression is more likely to weaken from lack of external support. It would be interesting to study this question in more detail.

Although numbers are small, we make some tentative observations regarding gender differentials in attitudes to science, with a larger proportion of boys agreeing that they want to become a scientist, could become a rocket scientist, or seen themselves as 'science people'. These findings are unsurprising in the light of existing research; however it is interesting to note that the trend is nullified, or even reversed, when it comes to more concrete questions. There was no gender difference in the proportion of girls and boys who envisaged studying science at post-compulsory level; this is maybe a reflection of the increasing number of girls studying science across the U.K., although this may conceal a differential between aspirations in physics/engineering and in other subjects. A further point of interest is that a greater proportion of girls than boys said they 'would like a job that uses science'; there is a clear distinction here between jobs that use science and 'being a scientist'. Here we find it useful to draw a distinction between 'identity' and 'realist' measures of science-related aspirations; while girls were less likely to see themselves in a 'sciencey' light, this had not at this stage prevented them from having 'realist' science ambitions. It will be interesting to see whether this effect persists with age among our cohort.

\subsubsection{Key findings}

- Some participants, particularly boys, demonstrated a 'concealed science identity' - they saw themselves as a 'science person' but did not think other people did

- Boys scored higher on generalised 'science identity' measures such as "I see myself as a science person" or "I could become a rocket scientist"

- However there was no difference between girls and boys on more 'realist' measures such as "I would like to have a job that uses science" 


\subsection{Science jobs and the utility of science qualifications}

\subsubsection{Jobs}

The ASPIRES study found that in years 6-9, the most popular career aspirations were "in the arts, sports, medicines and teaching". Our PIER findings were broadly in line with this, with the exception of arts careers. We would make the additional observation that many participants either cited future careers that they had direct experience of, or that were jobs that are prominent in everyday life. Among jobs mentioned were footballer, hairdresser, teacher and firefighter, while a few respondents mentioned science-related jobs such as doctor or vet.

Some participants were influenced in their career aspirations by family members. Ariana Grande, asked if she would like to become a scientist, said:

"I don't think I'd want to have that as my job because my family members, they have, like, other types of jobs that I'd like to do. I'm not really sure what I want to do yet. My auntie helps people, like a care worker, and she also helps children in schools, like, get through hard times."

Amelia, meanwhile, said:

"No. Because when I'm older I've been thinking about being a hairdresser instead of being a scientist. Don't really know why but when mum grew up she grew up being a hairdresser then she stopped. I think I'm just like my mum."

The few respondents who did react positively to the question "Do you think you would like to be a scientist?" were uniformly vague as to what this would entail:

"Yes. Work with potions and stuff."

"Work on space and stuff."

"Yes, because I want to, like, help get more people into science."

"Yes, because it's interesting and you get to do lots of different stuff. I'd like to go to space."

\subsubsection{Utility of science}

As previously mentioned, research shows that young people choosing post-compulsory science qualifications have a greater understanding of the utility of science. It follows that an understanding of the breadth of science's usefulness in the jobs market can be a good starting point for encouraging future science participation. On the face of it, the results of the initial PIER survey are positive on this point (Table 1).

These results seem to indicate a cohort that is well-informed about the usefulness of science in future life and the breadth of jobs that its study supports. However, when we probed this point more deeply in interviews, a different picture emerged. 
Table 1. Views of PIER cohort on a variety of science utility measures.

\begin{tabular}{|l|l|}
\hline Statement & $\begin{array}{l}\text { \% of PIER cohort agreeing } \\
\text { or strongly agreeing }\end{array}$ \\
\hline $\begin{array}{l}\text { A science qualification can help you get many different } \\
\text { types of job. }\end{array}$ & 71 \\
\hline $\begin{array}{l}\text { It is important to study science even if you don't want a } \\
\text { science job in the future. }\end{array}$ & 64 \\
\hline Science skills are useful for lots of future jobs. & 82 \\
\hline $\begin{array}{l}\text { Studying science could help me get a job in the Blackpool } \\
\text { area. }\end{array}$ & 72 \\
\hline
\end{tabular}

When we asked whether the interviewee thought that there were many jobs that used science, most who directly answered the question agreed either firmly $(19 / 38)$ or tentatively, for example "I think, like, some jobs will need science" (8/38).

However, when we asked participants to name some jobs that used science, a strong pattern emerged whereby pupils either named a very small range of jobs (teacher, medical jobs, space scientists), failed to think of any examples, or named jobs that were familiar to them but which are in reality only tangentially connected to science. This exchange with participant R3 illustrates the point well:
Interviewer: So, do you think there are many jobs out there... that need science or are involved with science?
R3: Yes, because some jobs like if you want to be a science teacher, then you need to know science.
Interviewer: OK, can you think of any other jobs or anything that you think you need science to do?
R3: A doctor, a vet... A builder, if you're mixing chemicals, you need to make solids.

Other examples given of 'familiar' jobs that might require science were firefighter and the police service, where one participant mused that a police officer might use the position of the sun to orient themselves and give directions.

This interview with Anna 319 illustrates a fundamental lack of information about science careers that lay behind some positive responses:

Interviewer: Are there many jobs, do you think, that use science?

Anna 319: Yes.

Interviewer: Can you think of any, what kinds of jobs use science?

Anna 319: Being a scientist.

Interviewer: OK, so what jobs need scientists in them? Let's put it like that.

Anna 319: I don't know.

A handful of respondents seemed to have a high level of information on the usefulness of science for their age group, as encapsulated by this response from Gladiator Galaxy: 
"Scientists, animal studies, habitat studies, once again linking to animals, biology, space, trying to find how physics works, that applies a bit to science too, so, like, gravity and stuff."

However such detailed responses were very rare amongst our cohort; in general, it seems that ideas about what a scientist "is" or "does", are underdeveloped among our participants.

\subsubsection{Discussion}

When it comes to science careers, the PIER cohort had clearly imbibed the message that studying science 'is useful for getting a good job in the future' - but there was little evidence of any understanding of what this might mean. Careers that a child might encounter in daily life - in healthcare, for example, or teaching - were cited as examples of science jobs, but outside of these there was a tendency for young people to try to find ways in which jobs they were familiar with could be parsed in 'sciencey' terms.

Pupils who do not understand where studying science may lead are less likely to continue with it at post-compulsory age; the choice, for example, to study post-16 physics is much more strongly influenced by career aspiration than by any other factor [Reiss, 2013]. This finding, therefore, presents an opportunity for the PIER programme to inform young people about science jobs, rather than just about science itself, and thus potentially influence later choices.

The fact that the 'science is useful' message had percolated to our group without carrying much real understanding of how this usefulness might present itself is rather worrying. It raises concerns that headline statistics indicating the views of young people on this point may be misleading. Future participation gains may potentially be achieved by anchoring utility information in real-world pursuits and careers.

\subsubsection{Key findings}

- Most participants agreed that it was useful to study science

- However they were largely unable to say why this might be, or to name many jobs that use science

Our findings underline the fact that young people from highly deprived backgrounds do not lack interest or aspirations in science when compared to the national cohort. On the contrary, our group were very interested in science, especially space science, and reported consuming science media.

However they also reinforce the thesis that aspirations among such groups cannot necessarily evolve into expectations; the 10/11 year olds in our cohort believed that their parents were interested in science and thought science was important at the same or higher levels than their peers nationally, but were already less likely to 
agree that their families expected them to go to university. The implication for science communicators, academics or institutions planning science interventions with low-participation groups is that a focus on 'aspirations' or 'generating interest' is unlikely to be effective; rather, the focus should be on helping these children to see continued science participation as a feasible future, both in terms of knowledge of careers that are available, and the ability to see themselves in those roles.

In terms of how our participants saw themselves in relation to science, we were interested to note a phenomenon of 'concealed science identity' among some children. In some cases, at least, we tentatively ascribe this to a conflict between an interest in science and the participant's sense of self - an incompatibility with the 'class joker' image of some boys, or with the self-described 'girly girl' image of some female participants. However for others a simple lack of opportunity to express their 'scientific side' may be a cause. Whether this phenomenon is a particular feature of our cohort is uncertain; one might speculate that children from high-science capital communities might feel less pressure to conceal their science interests, or have more opportunity to express them. It would be interesting to investigate the effects of suppressing scientific interests on future participation.

As might be expected from previous literature, girls were less positive about their sense of self in relation to science than boys in terms of what one might term 'identity' measures, such as intention to 'become a scientist'. However on what one might consider as 'realist' measures, such as having a career involving science or studying post-compulsory science, the difference disappeared or was reversed. As the PIER project involves the type of physical science in which girls are still significantly underrepresented, it will be interesting to see whether gender differences in the impact of the interventions are visible. It would also be interesting to study this on a longitudinal, non-intervention basis to investigate how this distinction between realist and identity measures between the sexes persists, or otherwise, with age.

When it comes to ideas about the utility of science, the study group have absorbed the message that it is useful to study science, but are unsure as to why. Participants' limited range of knowledge of science careers echoes that of the national picture, and it will be interesting to see if and how the PIER project can impact on this. More generally, it is worrying that pupils stated that science was useful but did not have the understanding to back this up; this suggests that methods used to disseminate this message are lacking in practical effectiveness, a message that may provide cause for reflection among the science communication community.

This study of attitudes to science and space science in a group of older primary children from a highly disadvantaged area holds several learning points for those planning WP interventions in schools. Such activities may be more effective if they focus on 'real-life' opportunities to pursue science rather than on aspiration-raising; if they provide space for 'concealed' science interests to be revealed; if they strengthen girls' beliefs that, despite the fact that they may not feel like 'science people', there could still be a future for them in science; and if they transmit practical information about the career opportunities that can be opened by studying science. Young people from less-advantaged cohorts are as enthusiastic about science as any other children; it is for the STEM WP and communication community to show them how this can be translated into a viable scientific future. 
Archer, L., Dawson, E., DeWitt, J., Seakins, A. and Wong, B. (2015). “'Science capital": a conceptual, methodological, and empirical argument for extending bourdieusian notions of capital beyond the arts'. Journal of Research in Science Teaching 52 (7), pp. 922-948. https: //doi .org/10.1002/tea. 21227.

Archer, L. and DeWitt, J. (2017). Understanding young people's science aspirations: how students form ideas about 'becoming a scientist'. London, U.K.: Routledge. https://doi.org/10.4324/9781315761077.

Archer, L., DeWitt, J. and Dillon, J. (2014). “It didn't really change my opinion': exploring what works, what doesn't and why in a school science, technology, engineering and mathematics careers intervention'. Research in Science and Technological Education 32 (1), pp. 35-55. https://doi.org/10.1080/02635143.2013.865601.

Archer, L., DeWitt, J. and Wong, B. (2014). 'Spheres of influence: what shapes young people's aspirations at age $12 / 13$ and what are the implications for education policy?' Journal of Education Policy 29 (1), pp. 58-85. https://doi.org/10.1080/02680939.2013.790079.

Archer, L., Osborne, J., DeWitt, J., Dillon, J., Wong, B. and Willis, B. (2013). Young people's science and career aspirations, age 10-14. URL: https://kclpure.kcl. ac.u $\mathrm{k} / \mathrm{portal} / \mathrm{files} / 64130521 /$ ASPIRES_Report_2013.pdf.

Archer, L. and Tomei, A. (2013). 'What influences participation in science and mathematics?' A briefing paper from the Targeted Initiative on Science and Mathematics Education (TISME). URL: https://kclpure.kcl.ac.uk/portal/fil es/64435093/TISME_briefing_paper_March_2013.pdf.

Baker, W., Sammons, P., Siraj-Blatchford, I., Sylva, K., Melhuish, E. C. and Taggart, B. (2014). 'Aspirations, education and inequality in England: insights from the Effective Provision of Pre-school, Primary and Secondary Education Project'. Oxford Review of Education 40 (5), pp. 525-542. https://doi.org/10.1080/03054985.2014.953921.

Banerjee, P. A. (2017). 'Is informal education the answer to increasing and widening participation in STEM education?' Review of Education 5 (2), pp. 202-224. https://doi.org/10.1002/rev3.3093.

Boxer, P., Goldstein, S. E., DeLorenzo, T., Savoy, S. and Mercado, I. (2011). 'Educational aspiration-expectation discrepancies: relation to socioeconomic and academic risk-related factors'. Journal of Adolescence 34 (4), pp. 609-617. https://doi.org/10.1016/j.adolescence.2010.10.002.

Canovan, C. (2019). "“Going to these events truly opens your eyes". Perceptions of science and science careers following a family visit to a science festival'. JCOM 18 (02), A01. https://doi.org/10.22323/2.18020201.

Cleaves, A. (2005). 'The formation of science choices in secondary school'. International Journal of Science Education 27 (3), pp. 471-486. https://doi.org/10.1080/0950069042000323746.

Cochrane, M. (2010). 'Do role models help to widen participation? An investigation into the effect of social background on choice of role model'. Widening Participation and Lifelong Learning 12 (1), pp. 7-17.

URL: http://wpll-journal .metapress . com/content/1818718r43530415.

Department for Business Energy and Industrial Strategy (2017). Industrial Strategy: the 5 foundations.

URL: https://www.gov.uk/government/publications/industrial-strategythe-foundations/industrial-strategy-the-5-foundations\%5C\#people. 
Department for Business Energy and Industrial Strategy (2018). Industrial Strategy: building a Britain fit for the future. URL: https://www. gov . uk/government/public ations/industrial-strategy-building-a-britain-fit-for-the-future.

Education and Skills Funding Agency (2016). Pupil premium: allocations and conditions of grant 2016 to 2017. URL: https: //www. gov . uk/government/publica tions/pupil-premium-conditions-of-grant-2016-to-2017.

- (2017). Pupil premium: allocations and conditions of grant 2017 to 2018. URL: https://www.gov.uk/government/publications/pupil-premium-condit ions-of-grant-2017-to-2018.

Greaves, E. and Crawford, C. (2013). A comparison of commonly used socio-economic indicators: their relationship to educational disadvantage and relevance to Teach First. URL: https://doi.org/10.1920/re.ifs.2013.0079.

Grove, M. (2013). National HE STEM Programme - Final report. URL: https://www.birmingham.ac.uk/Documents/college-eps/college/stem /national-he-stem-programme-final-report.pdf.

Harrison, N. and Waller, R. (2018). 'Challenging discourses of aspiration: the role of expectations and attainment in access to higher education'. British Educational Research Journal 44 (5), pp. 914-938. https: //doi .org/10.1002/berj . 3475.

Higher Education Statistics Agency (2018). Widening participation: UK Performance Indicators 2017/18. URL: https://www .hesa.ac.uk/news/07-02-2019/widening -participation-tables.

Hill, D. and Wheeler, A. (1991). 'Towards a clearer understanding of students' ideas about science and technology: an exploratory study'. Research in Science $\mathcal{E}$ Technological Education 9 (2), pp. 127-137. https://doi.org/10.1080/0263514910090202.

Hobbs, L., Stevens, C., Hartley, J. and Hartley, C. (2019). 'Science Hunters: an inclusive approach to engaging with science through Minecraft'. JCOM 18 (02), N01. https://doi.org/10.22323/2.18020801.

Illingworth, S., Lewis, E. and Percival, C. (2015). 'Does attending a large science event enthuse young people about science careers?' JCOM 14 (02), A06. https://doi.org/10.22323/2.14020206.

Joint Council for Qualifications (2019). Main results tables. URL: https: //www.jcq.org. uk/examination-results/.

Khattab, N. (2015). 'Students' aspirations, expectations and school achievement: what really matters?' British Educational Research Journal 41 (5), pp. 731-748. https://doi.org/10.1002/berj.3171.

Kirby, P. and Cullinane, C. (2016). Class differences: ethnicity and disadvantage. URL: https://www. suttontrust.com/our-research/class-differences-ethn icity-and-disadvantage/.

OECD (2015). The ABC of gender equality in education. URL: https://doi .org/10.1787/9789264229945-en.

Office for Students (2018). Our new approach to access and participation. URL: https: //www. officeforstudents.org.uk/advice-and-guidance/promoting-equalopportunities/our-new-approach-to-access-and-participation/.

- (2019). Young participation by area. URL: https://www . officeforstudents . org.u $\mathrm{k} /$ data-and-analysis/young-participation-by-area/.

Osborne, J., Simon, S. and Collins, S. (2003). 'Attitudes towards science: a review of the literature and its implications'. International Journal of Science Education 25 (9), pp. 1049-1079. https://doi .org/10.1080/0950069032000032199. 
Reiss, M. J. (2013). How can we get more students to study mathematics or physics? The UPMAP Project.

URL: https://www.ucl.ac.uk/ioe/sites/ioe/files/RB2_UPMAP_Reiss.pdf.

Robinson, D. and Salvestrini, V. (2020). The impact of interventions for widening access to higher education: a review of the evidence. URL: https://epi . org. uk/publicatio ns-and-research/impact-of-interventions-for-widening-access-to-he/.

St. Clair, R., Kintrea, K. and Houston, M. (2013). 'Silver bullet or red herring? New evidence on the place of aspirations in education'. Oxford Review of Education 39 (6), pp. 719-738. https://doi.org/10.1080/03054985.2013.854201.

UCAS (2017). Largest ever proportion of UK's 18 year olds entered higher education in 2017, UCAS data reveals. URL: https://www .ucas . com/corporate/news-and-key -documents/news/largest-ever-proportion-uks-18-year-olds-entered-hi gher-education-2017-ucas-data-reveals.

Wade, J. (2016). 'The UK Space Design Competition'. Young Scientists Journal; Canterbury Fasc. 19, pp. 58-59. URL: https://search.proquest.com/docview/1 807741438?pq-origsite=gscholar\&fromopenview=true.

Authors

Cherry Canovan is a research associate at the University of Central Lancashire. She obtained her PhD in Mathematical Physics from Lancaster University and previously worked as an education journalist. Her research interests include the impacts of science communication endeavours, particularly science festivals, as well as widening participation in STEM and higher education more generally. E-mail: ccanovan@uclan.ac.uk.

Robert Walsh is a professor of Solar Physics in the Jeremiah Horrocks Institute at the University of Central Lancashire, Preston. Currently he is an STFC Leadership Fellow in Public Engagement, focusing on working with low science capital audiences in Blackpool, Lancashire. Recently Robert created the art/science installation called SUN, a seven-metre diameter suspended sphere, internally projected with images from NASA's Solar Dynamics Observatory. Robert is the U.K. National Outreach Coordinator for the International Astronomical Union and an Honorary life member of the Royal Institution. Working with the Ri, Robert helped create the Ri-UCLan Young Scientist Centre on the Preston campus. E-mail: rwwalsh@uclan.ac.uk.

\section{How to cite}

Canovan, C. and Walsh, R. (2020). 'A space to study: expectations and aspirations toward science among a low-participation cohort'. JCOM 19 (06), A04. https://doi.org/10.22323/2.19060204. 